\title{
Results of Simulation of Faults of Starter Batteries
}

\author{
Andrey Puzakov ${ }^{1, *}$ \\ ${ }^{1}$ Orenburg State University, Pobedy avenue, 13, Orenburg, Russian Federation
}

\begin{abstract}
During the operation of the battery, its parameters change, declining with the rate affected by the natural aging processes or faults. To obtain information about changes in the parameters of the battery when the faults occur and develop, methods of their simulation have been developed. The change in the battery voltage under the influence of the reference load is determined to reduce the charging rate, oxidation of the pole terminals, and plates sulfatation. It is established that the health of state of old and faulty batteries at the same voltage differs significantly, which can be used to identify the technical condition of starter batteries.
\end{abstract}

\section{Introduction}

Battery faults are determined by the driver by indirect signs since a car is not equipped with devices for diagnosing its technical condition. This reduces the efficiency of car operation, since replacing or charging the battery is accompanied by time and material costs. Therefore, determining the technical condition of the car battery in the car is an urgent task.

During the operation of the battery, its parameters change, declining with the rate affected by the natural aging processes or faults.

The main faults of starter batteries are decrease in the state of charge (34\% of all faults), oxidation of the pole terminals (18\%), melting of the active mass (14\%), short circuit $(12 \%)$, plates sulfation $(10 \%)$, accelerated self-discharge $(8 \%)$, circuit breakage inside the battery $(4 \%)[1-5]$.

To obtain information about changes in the parameters of the battery when the faults occur and develop, methods of their simulation have been developed, discussed in detail in [6]. The purpose of this article is to process the results obtained during the simulation of the starter battery faults.

In the absence of load, the output parameters of the starter battery (Fig. 1) are described by the following expressions

$$
\left\{\begin{array}{c}
E=\Sigma E_{i} \\
r_{b}=\Sigma r_{i} \\
I_{b}=0
\end{array}\right.
$$

where $E$ is the electromotive force (no-load voltage) of the battery, $\mathrm{V} ; E_{i}$ - electromotive force (no-load voltage) of the battery, $\mathrm{V} ; i$ - number of accumulators in the battery; $r_{b}-$

\footnotetext{
*Corresponding author: and-rew78@yandex.ru
} 
internal resistance of the battery, ohms; $r_{i}$ - internal resistance of the battery, ohms; $I_{b}-$ discharge current of the battery, A.

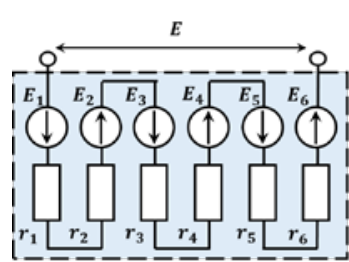

a)

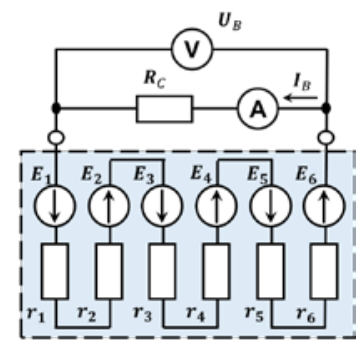

b)

a) without load; b) when loading

Fig. 1. Battery Output Parameters

When loading, the battery begins to generate an electric current, the value of which is determined by Ohm's law for a complete electrical circuit. The voltage at the battery terminals is reduced

$$
\left\{\begin{array}{c}
I_{b}=\frac{E}{R_{C}+r_{b}} \\
U_{b}=E-I_{b} \cdot\left(R_{C}+r_{b}\right)
\end{array}\right.
$$

where $R_{C}$ is the electrical resistance of the load, ohms; $U_{b}$ - battery voltage on load, V.

Changes in the health of batteries due to aging or faults can be estimated using the voltage when exposed to a reference load. During operation [7], the starter motor acts as such a load when starting an internal combustion engine (ICE).

$$
S O H=\frac{U_{c r}-U_{1}}{U_{n e w}-U_{1}}
$$

where $U_{c r}$ is the current battery voltage value when ICE starting, $\mathrm{V} ; U_{\text {new }}$ - maximum voltage value when starting the ICE with a new battery, $\mathrm{V} ; U_{1}$ - minimum permissible voltage sufficient for ICE starting, V.

In the laboratory, this operation mode is difficult to provide. The closest to it is the operation of the starter motor in the mode of full braking (short circuit), which exists for a short time even when ICE starting [8].

In this mode, the connection of measuring instruments is shown in Fig. 2. The duration of loading under the starter motor operating conditions should not exceed 5 seconds.

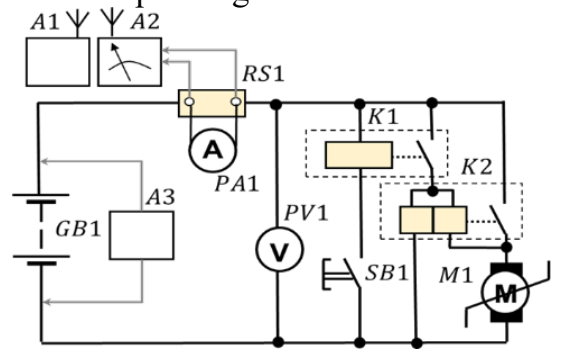

A1 - smartphone; A2 - OWON B41t + multimeter; A3 - HOBO UX120-006M analog data logger; GB1 - 6CT-60L starter battery; K1 - remote mass switch; K2 - solenoid starter switch; M1 - 2120-3708010 starter motor ; PA1-ammeter; PV1 - voltmeter; RS1 - current shunt 1000 A; SB1 - start button.

Fig. 2. Electrical Test Circuit 


\section{Reducing the State of Charge of the Battery}

A decrease in the state of charge of the battery most often occurs due to non-compliance with the car power balance. In other words, the battery does not have time to restore the energy spent on ICE starting. Also, a decrease in charge can occur due to many consumers or a generator fault. Thus, the discharge of the battery is mistaken for a fault. The decrease in charge is characterized, first, by a decrease in the voltage at the terminals, which leads to possible interruptions in the consumer operation.

The state of charge of the battery can be determined by Formula [9-11]

$$
S O C=\frac{U_{i}-U_{\min }}{U_{\max }-U_{\min }}
$$

where $\quad U_{i}$ - current voltage at the terminals, $\mathrm{V} ; U_{\max }$ - fully charged battery voltage, $\mathrm{V}$; $U_{\min }$ - voltage of the fully discharged battery, V.

To obtain the required $S O C$ values, the battery was forcibly discharged to the voltage values of 12.46 and $12.31 \mathrm{~V}$, respectively. These voltages correspond to $S O C=75 \%$ and $S O C=50 \%$. According to the standard, it is not allowed to use batteries that are less than $50 \%$ charged in the car. A fully charged battery pack had a voltage of $12.72 \mathrm{~V}$.

The experiments were carried out on Tyumen Battery Standard 6CT-60L batteries with a nominal capacity of $60 \mathrm{Ah}$.

As follows from Fig. 3, the voltage at the end of the loading mode changes slightly with a decrease in the battery charge. A decrease in the charge to the value of $S O C=50 \%$ caused a decrease in the voltage under loading by only $10 \%$. Therefore, during normal operation of the battery in the car, a decrease in its charge will not worsen its starting properties. However, this is typical only for a relatively new battery since its properties deteriorate with aging even at $S O C=100 \%$ (Fig. 4).

An increase in the service life of up to 8 years (Delkor battery) caused a $72 \%$ reduction in the voltage under loading.

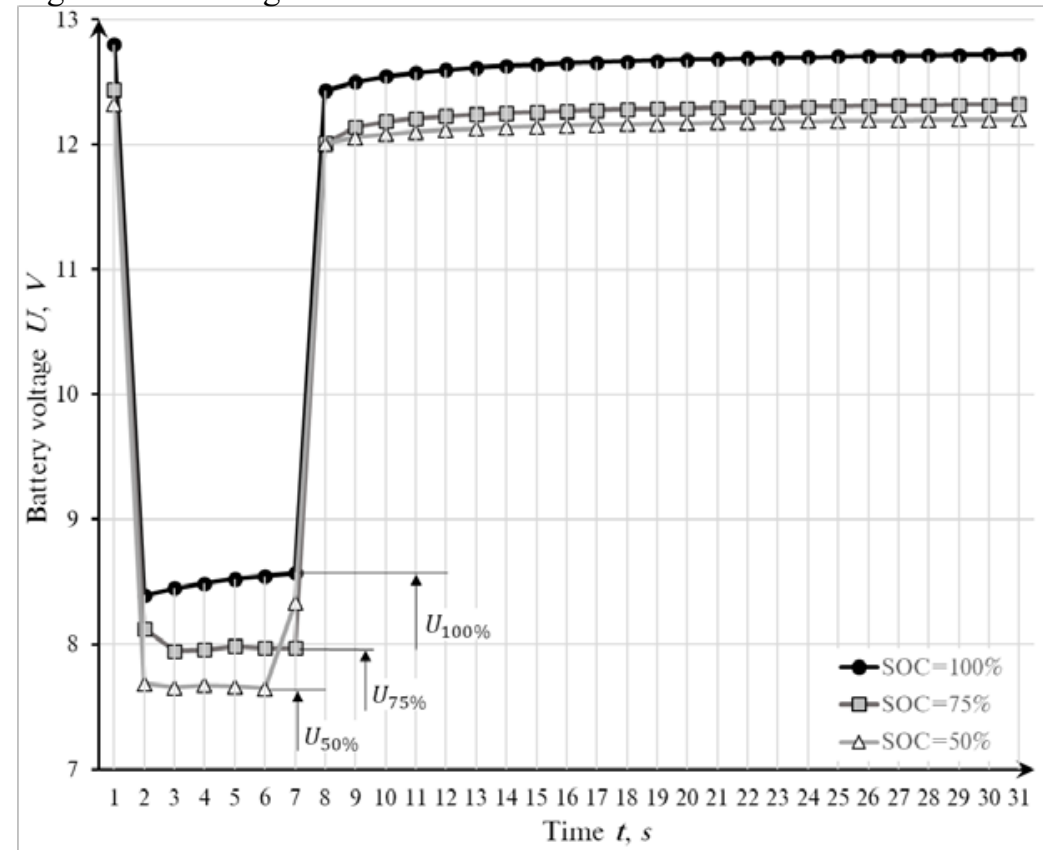

Fig. 3. Change in the Battery Voltage When the Battery Charge Decreases 


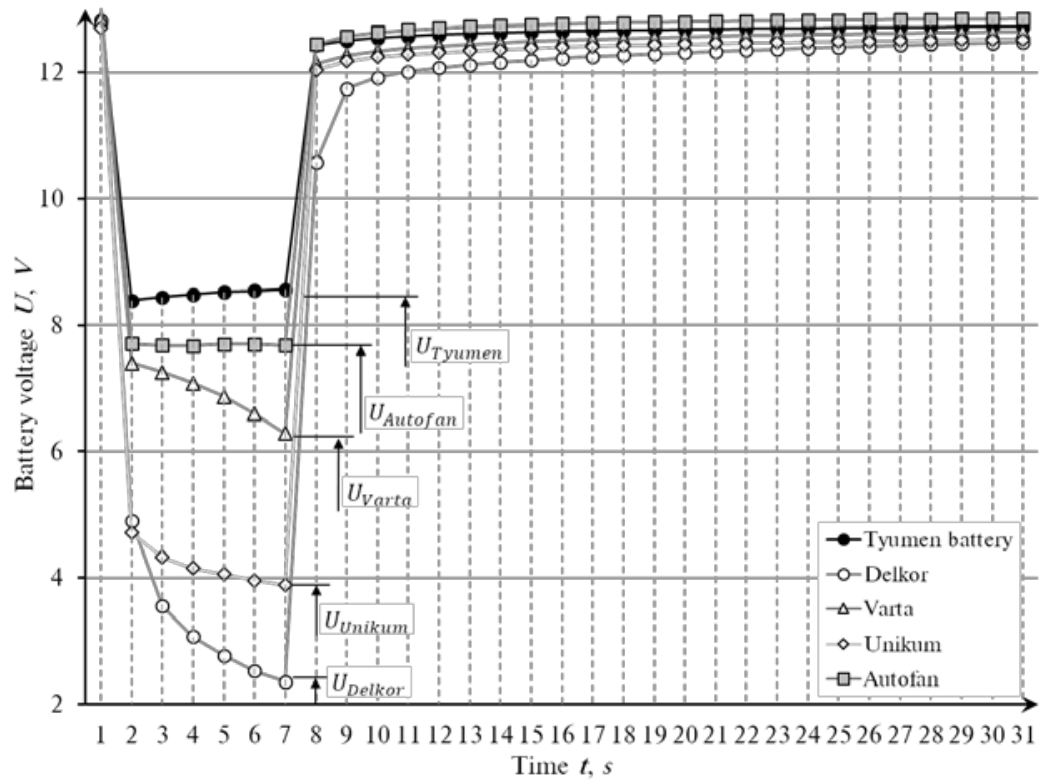

Fig. 4. Change in the Battery Voltage During Aging

\section{Oxidation of the Battery Pole Terminals}

Oxidation of the pole terminals may occur due to non-compliance with the battery maintenance rules. Such a fault can be characterized by a decrease in the current, both given and received by the battery due to an increase in the resistance in its circuit.

To simulate the oxidation of the pole terminals, the active electrical resistance is connected in series with the battery. In the loading mode, in this case, the discharge current and the voltage at the battery terminals are reduced due to the voltage drop at the resistor (Fig. 5).

$$
\left\{\begin{array}{c}
I_{b}=\frac{E}{R_{C}+r+R} \\
U_{b}=E-I_{b} \cdot\left(R_{C}+r+R\right)
\end{array}\right.
$$

where $R$ is the additional electrical resistance, ohm.

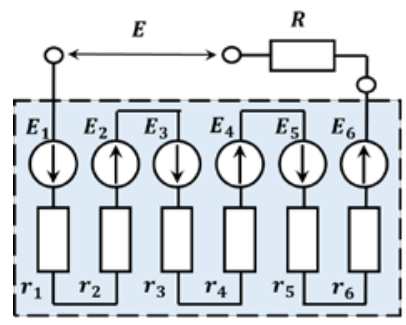

a)

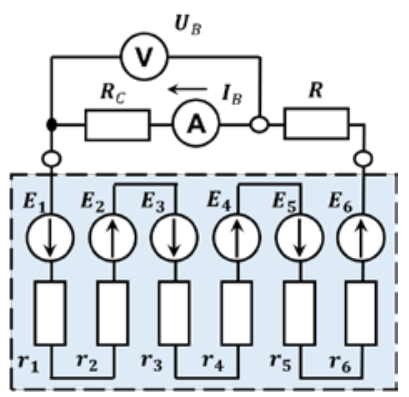

b)

a) without load; b) when loading

Fig. 5. Output Parameters of the Battery When Simulating the Oxidation of the Pole Terminals 
Initially, the nichrome helix was supposed to be used as an additional resistance, since it is often used in resistors. Unfortunately, nichrome has a high electrical resistivity. To obtain a resistance of 20 milliohm, we had to use a small $(50 \mathrm{~mm})$ section of a spiral with a diameter of $2 \mathrm{~mm}$. During loading, the nichrome wire burned out almost instantly.

The next option was to use a resistor from the battery cell tester. This device operation is intended for a sufficiently sustained load with a high current, which means that the resistor must withstand our experiments. As a result, it was possible to conduct a full test cycle for additional resistance values of 11.5 milliohm, 20 milliohm, and 40 milliohm.

Fig. 6 shows the results of the experiment. Oxidation of the pole terminals leads to a decrease in the battery voltage, which affects the starting properties. Also, this fault complicates the process of replenishing the charge from the generator.

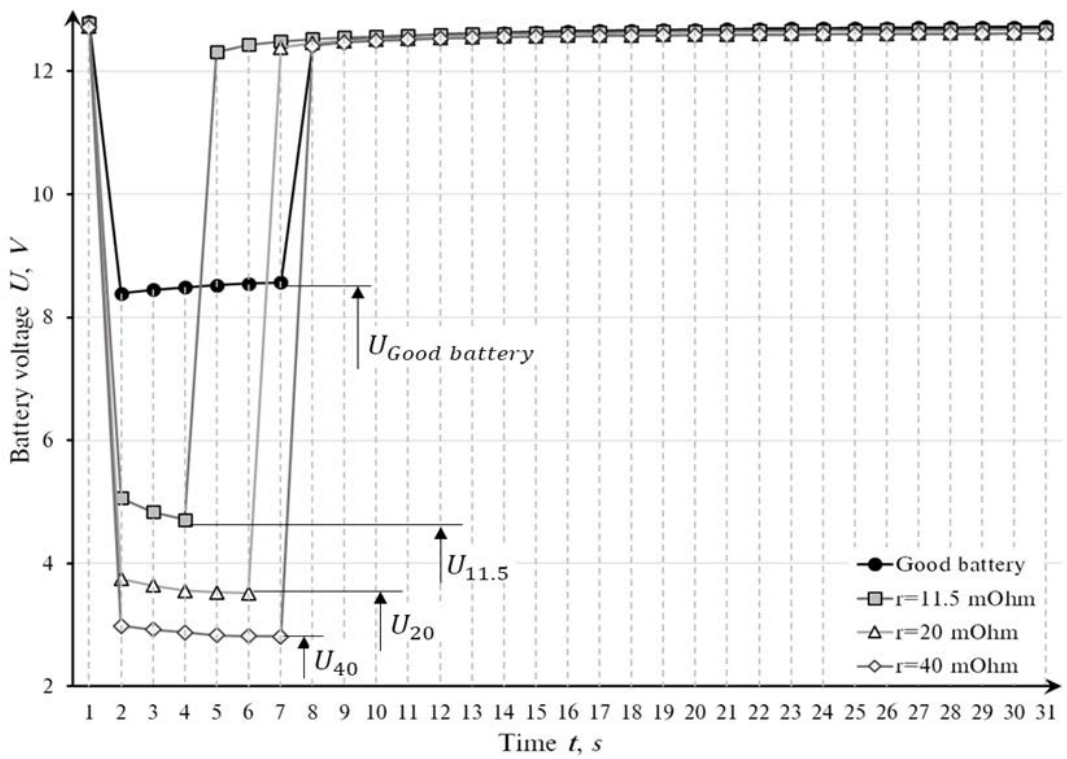

Fig. 6. Change in the Battery Voltage When Simulating the Oxidation of the Pole Terminals

\section{Sulfation of the Battery Plates}

Due to the formation of lead sulfur crystals on the plate surface, their active area decreases [12]. This can be simulated by lowering the electrolyte level below the upper edge of the plates. The exposed part of the plates is covered with lead sulfate $\mathrm{PbSO}_{4}$ (Fig. 7).

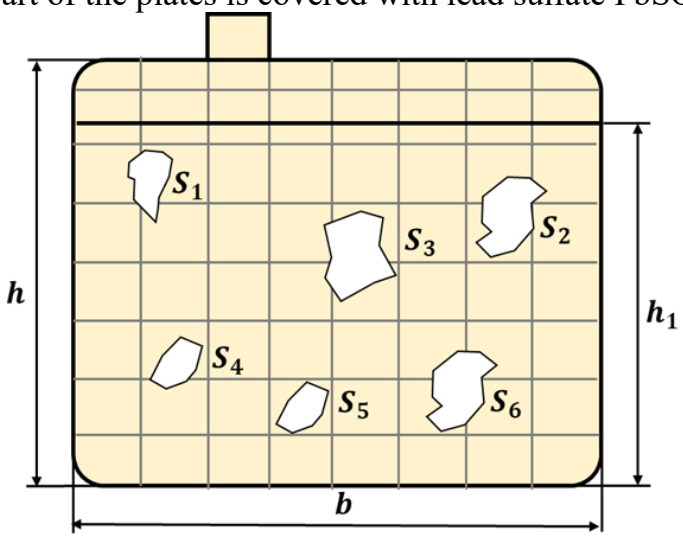

Fig. 7. Simulation of Plate Sulfation 
The total area of the plate is defined by the expression

$$
S=h \cdot b
$$

where $S$ is the plate area, $\mathrm{mm}^{2} ; h$ is the plate height, $\mathrm{mm} ; b$ is the plate width, $\mathrm{mm}$.

The active area of the plate during sulfation is determined by the expression

$$
S^{\prime}=S-\sum_{i=1}^{n} S_{i}
$$

where $S^{\prime}$ is the active area of the electrode, $\mathrm{mm}^{2} ; n$ is the number of sulfation spots; $S_{i}$ is the area of all sulfation spots, $\mathrm{mm}^{2}$.

The simulated active area of the plate is determined by the expression

$$
S_{1}=h_{1} \cdot b
$$

where $S_{1}$ is the simulated active area of the plate, $\mathrm{mm}^{2} ; h_{1}$ is the level of the electrolyte in the battery, $\mathrm{mm}$.

By the simulation condition

$$
S_{1}=S^{\prime}
$$

The experiment was conducted in the following order. Holes were drilled in the side surface of the battery to drain the electrolyte. At the first stage, the holes were drilled at $1 / 2$ of the plate height, in one, three, and six accumulators, respectively. Then the holes were made at $1 / 5$ of the plate height in three and six accumulators. Thus, five stages of the sulfation development were studied.

The results of the experiment are shown in Fig. 8. Reducing the active area of the battery plates to $20 \%$ of the rated area (Stage 5 ) resulted in a voltage reduction of only $20 \%$.

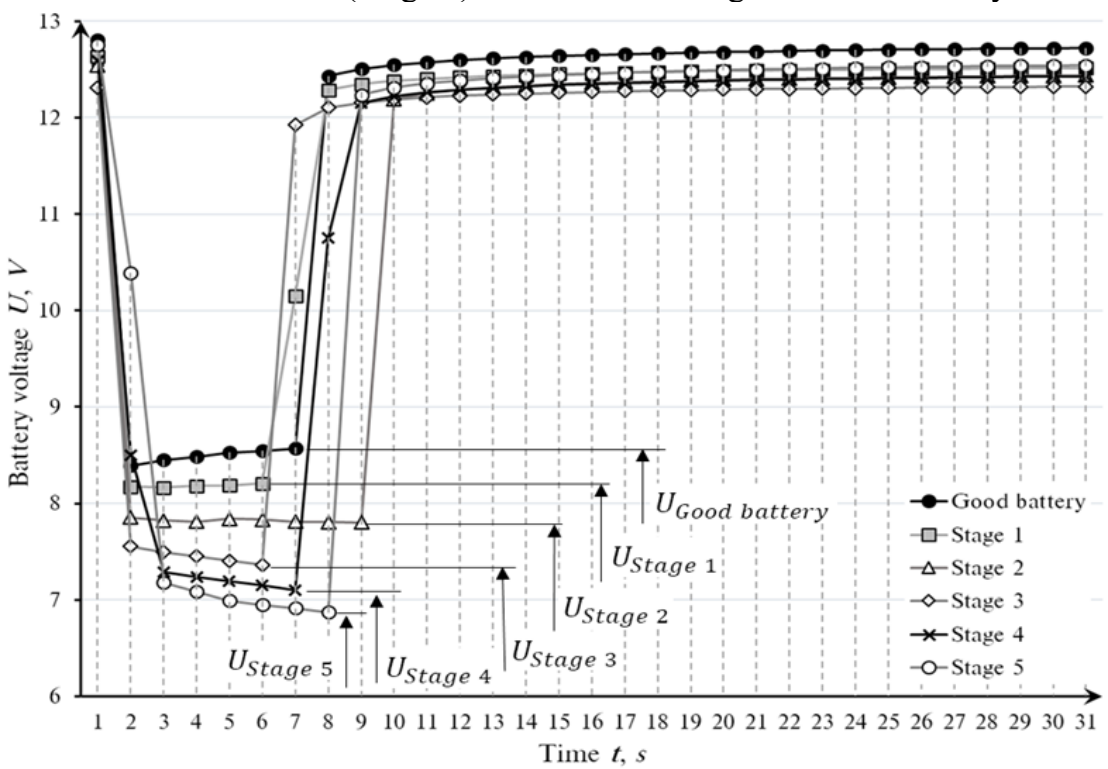

Fig. 8. Change in the Battery Voltage When Simulating the Plates Sulfation 


\section{Discussion of the results and conclusions}

Substituting the values of the loading mode voltages established experimentally during the simulation of the battery faults in Formula (3), we obtain the state of health $\mathrm{SOH}$. The relationship between the voltage and the state of health is shown in Fig. 9, where the light markers highlight the results of the calculation according to Formula (3), based on which the trend line is made.

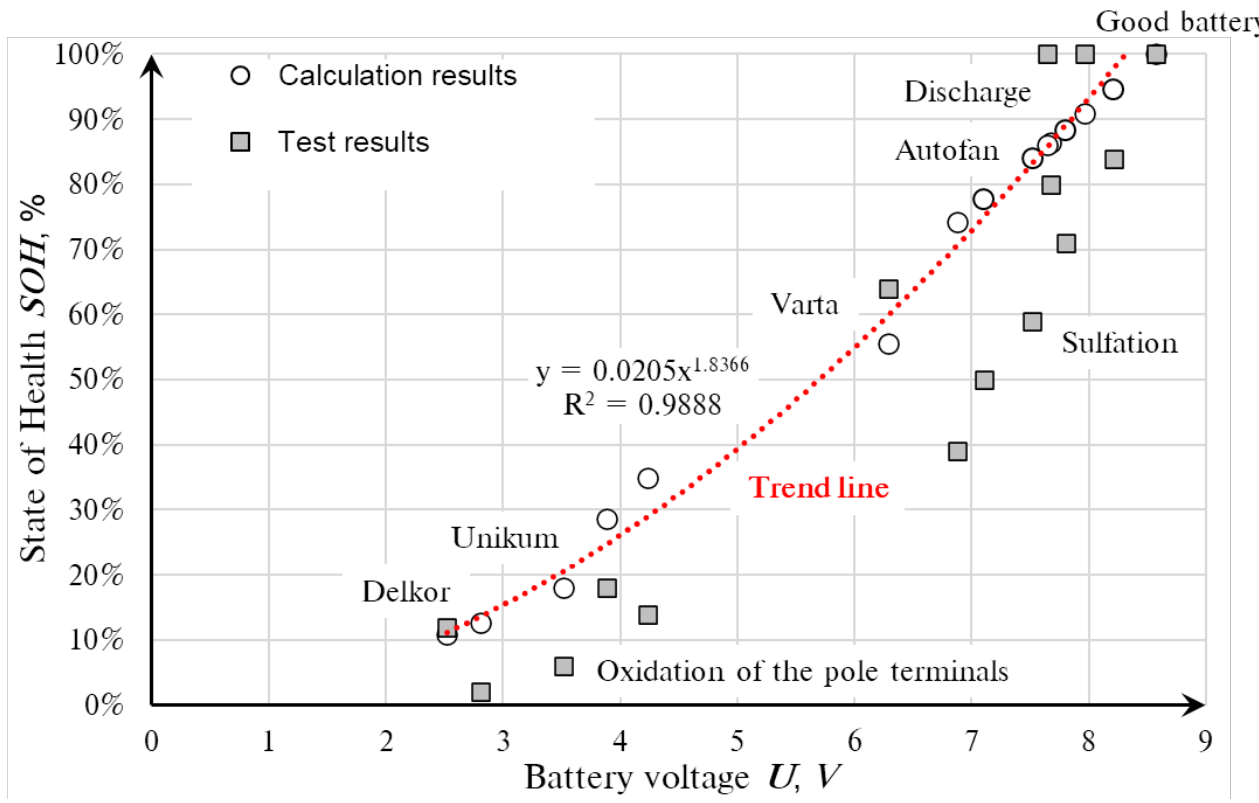

Fig. 9. Results of Changing the State of Battery Health During Fault Simulation

Also in Fig. 9, the dark markers indicate the results of finding the state of health $\mathrm{SOH}$, using the ICartool IC-110 tester. To determine the $\mathrm{SOH}$, the following expression is used in the tester

$$
S O H=\left(\frac{I_{i}}{I_{C C A}}\right)^{2}
$$

where $S O H$ is the state of health, in unit fractions, $I_{i}$ is the actual value of the battery current, A; $I_{C C A}$ is the cold cranking amperes, A.

Analyzing the position of the markers, we can draw the following conclusions:

- the results of the experiment and the tester data converge for a serviceable battery and charged batteries with different operating time;

- the health values obtained during the fault simulation differ significantly, which is explained by the fact that the current value is used in the tester, and the battery voltage value is used in Formula (3)

Thus, the calculation according to Formula (3) gives an overestimated result for faulty batteries, but the difference in the results can be used to identify faults. 


\section{References}

1. K. Brik, F. Ammar, The Fault tree analysis of the lead acid battery's degradation, Journal of Electrical Systems, 4-2. pp. 1-12 (2008)

2. O. Demirci, B. Demirci, S. Taskin, Battery Cell Measurement and Fault Diagnosis System for Detection of Problem in Automotive Batteries, Pamukkale University Journal of Engineering Sciences, 25, pp. 546-552 (2019)

3. R. Yahmadi, K. Brik, F. Ammar, Failures analysis and improvement lifetime of lead acid battery in different applications, Proceedings of Engineering \& Technology (PET), pp. 148-154 (2016)

4. S.N. Zhang, P. Xie, R.S. Yang, T.Z. Shao, The Failure Analysis and Countermeasures of Starter Battery, Advanced Materials Research, 805-806, pp. 515-518 (2013)

5. S. Schwimmbeck, P. Schroer, Q. Buchner, H.-G. Herzog, Modeling the Dynamic Behavior of $12 \mathrm{~V}$ AGM Batteries and Its Degradation, 2019 IEEE Vehicle Power and Propulsion Conference, pp. 1-6 (2019)

6. A. Puzakov, D. Smirnov, Physical simulation of the faults of starter batteries, IOP Conf. Ser.: Mater. Sci. Eng. 971052066 (2020)

7. E. Meissner, G. Richter, The challenge to the automotive battery industry: the battery has to become an increasingly integrated component within the vehicle electric power system, Journal of Power Sources, 144(2), pp. 438-460 (2005)

8. A. Puzakov, Development of the load cycle of the starter battery, IOP Conf. Ser.: Mater. Sci. Eng. 971052064 (2020)

9. M. Danko, J. Adamec, M. Taraba, P. Drgona, Overview of batteries State of Charge estimation methods, Transportation Research Procedia. 40. pp. 186-192 (2019)

10. T. Kataoka, H. Takechi, A. Hatanaka, Y. Yamaguchi, T. Matsuura, Y. Matsutani, Battery State Estimation System for Automobiles, Sei Technical Review, 88, pp. 55-58 (2019)

11. V. Prasad, B. Divakar, Real Time Estimation of SOC and SOH of Batteries, International Journal of Renewable Energy Research, 8, pp. 44-55 (2018)

12. H. Catherino, F. Feres, F. Trinidad, Sulfation in lead-acid batteries. Journal of Power Sources, 129, pp. 113-120 (2004) 